\title{
Self-mutilation: culture, contexts and nursing responses
}

\author{
LIAM CLARKE BA, MSc, PhD, RN, Dip Nurs, Dip Ed, Dip Theol \\ Senior Lecturer, University of Brighton, Falmer, Brighton, UK \\ MARGARET WHITTAKER BA, RN \\ Staff Nurse, Community Rehabilitation Team, Queen Charlotte's Hospital, Hastings, UK \\ Accepted for publication 29 Fuly 1996
}

\section{Summary}

- Few papers address the issue of deliberate self-mutilation other than from clinical perspectives.

- This paper advocates a user-perspective and discusses some of the issues which might attend such a change.

- The occurrence of self-mutilation is placed within a cultural framework so as to enlarge the debate beyond the confines of medical/nursing responses.

- It is suggested that nurses abrogate their attachment to such responses and embrace more collaborative approaches to care.

- In particular, nurses are asked to review their (moral) responses to self-mutilation, an activity which, too often, has been responded to with scorn and derision.

Keymords: attitudes, culture, self-harm, self-mutilation

\section{Introduction}

In the vast repertoire of human suffering and folly, few activities rank as puzzling as self-mutilation. Our aim is a critical discussion of this area, including a cultural overview, the reasons behind this behaviour plus some suggestions about nursing responses to it.

Clinicians and researchers agree that acts of selfmutilation may be split into three 'categories': self-mutilative acts as part of a psychotic illness, stereotypical acts of self-harm which are linked to an organic aetiology, e.g. Tourette's Syndrome (Robertson et al., 1989), and 'moderate self-mutilation' (Favazza, 1989). It is this last category that concerns us as it appears to be the least understood, receives the least attention from researchers and yet remains a very complex, mismanaged and somewhat isolated aspect of mental health. Moderate self-mutilation, especially by cutting the arms, provokes intense reactions amongst nursing and other professionals and is linked to a multitude of psychiatric diagnoses. We recognize that the phrase 'moderate self-mutilation' may cause some offence since there is nothing moderate about the kinds of emotions which provoke this behaviour, or the actual destructive act itself (Pembroke, 1991), and we do indeed recognize this. However, we require a term of reference and shall use self-mutilation as, arguably, it is less objectionable than 'cutters and burners' (Favazza \& Rosenthal, 1990) or 'wrist slashers' (Simpson, 1976).

\section{Self-mutilation: a cultural overview}

The word mutilation derives from the Latin 'mutilus', to 'render imperfect, destroy the use, or deprive of a limb or organ' (Concise Oxford Dictionary). Such a succinct descrip- 
tion fails, of course, to provide any indication as to its complex nature and the multitudinous issues surrounding it. We are emphasizing self-mutilation as a culturally defined phenomenon so as to provide a complete, more wellrounded picture, because we believe that if nurses are to escape the rather isolated realms of clinical diagnosis and treatments, then they must synthesize their knowledge within the context of their culture and history.

The Judeo-Christian tradition contains many references to self-mutilative behaviour: in 1 Kings 18:28 the priests of Baal 'began calling at the top of their voice and cutting themselves according to their custom'. In the New Testament, Paul admonishes his listeners to 'avoid those mutilating the flesh' (Philippians 3:2) and, most famously, in Mark's Gospel (Ch 9, 43-47) there occurs the admonition: 'If your hand causes you to sin, cut it off ... and if your eye causes you to sin, pluck it out'. Two centuries later, Origen, the great Alexandrian theologian, would castrate himself in an act of motivation towards greater asceticism, and such practices continued largely unabated until the coming of the 'New Learning' towards the end of the middle ages. Although less extreme in execution, selfmaiming or marking remains and, indeed, appears to have increased quite dramatically over the last 30 years in the West (Weismann, 1974; Wexler et al., 1978).

\section{Ornamentation}

Indeed, Favazza (1989) maintains that: self-mutilation is not alien to the human condition, rather it is culturally and psychologically embedded in the profound, elemental experiences of healing, religion and social amity. (p. 142)

However, the schism between what is thought acceptable and what is considered repulsive is usually blurred by the cultural norms of the day. Favazza (1987), for instance, would include tattooing, blood letting and body piercing within his encompassing term 'modern primitivism', and he interprets Western self-mutilative acts as emulating those found in primitive groups in non-Western countries. Gardner \& Gardner (1975) observed that female self-mutilators are, on the whole, well groomed and they somewhat fancifully conclude that skin cutting is an extension of the grooming process, noting along the way McEvedy's (1963) point that in the West females:

devote a great deal more time to such grooming activities as skin and hair care. (p. 127)

Gardner \& Gardner go on to liken such behaviour to that of female members of some African tribes who sport facial decorative scars. We, however, regard comparisons of selfinjurious acts which are part of culturally sanctioned rites of passage with culturally deviant acts of female narcissism in the West as dubious. Favazza (1989), for example, reports that African tribeswomen do not possess any of the accompanying reasons, feelings or emotions for committing selfmutilating acts which appear part and parcel of the motives of their Western counterparts. Indeed, the general consensus amongst European and American researchers has been that self-mutilators in the West constitute (largely) primitive, morbid attempts by, particularly, troubled teenagers to overcome seemingly unsolvable problems. Simpson (1975) concurs, arguing that self-mutilation is linked to poor body image and is, in fact, an external act of distress.

Comparisons between cultures are highly speculative especially as they often take no account of diverse meanings mithin cultures. Arguably, in our culture, mutilative behaviours are more tolerated than accepted, and are seen as a mode of expression perhaps, and as ritual acts which give young individuals a sense of belonging to a contemporary group. Membership of the punk 'movement', for example, required clear insignia in terms of dress and facial makeup. Even more strikingly did punks sport safety pins and other metal bits pierced through the lips, nose, eyebrows and so on. More recently still, piercing the face has become even more widespread, albeit participants do not appear to comprise an identifiable group other than being, in the main, adolescents and young adults. Whether culturally sanctioned or regarded as deviant, these behaviours may work to attain the same ends of giving some (youthful) individuals a measure of control over their lives.

\section{Skin}

Skin is symbolically important not only because it is the barrier upon which damage is inflicted but also because it portrays by its colour and condition a gamut of emotions: rage, fear, embarrassment and so on. In many ways, it is the border between the outer world and the inner world, the environment and the self (Favazza \& Rosenthal, 1990), a living canvas by which a person - by marking or damaging - communicates a range of ideas or emotions. Such acts of mutilation, of course, invoke intense feelings amongst the outer world community of which nurses are an integral part; consequently, they can be seen as attention-seeking or manipulative acts or, in some cases, as impossibly vulgar or aggressive. Alternatively, from a psychological perspective, they may be regarded as cathartic and disciplined acts of self-preservation. Certainly, many would agree with Podvoll (1969) that the continuation or cessation of selfmutilation will depend heavily upon the community's reaction. We contend that where that reaction fails to take account of the self-injury as a cathartic challenge to feelings 
of oppression or 'social suffocation', then further selfinjury is likely.

\section{A female affliction?}

Morgan (1979) reports a 'horrific' rise in self-mutilation throughout the 1960s and 1970s, especially amongst young women: increases in Bristol for adolescents between 15 and 20 years old were of the order of 18 times for females and 4.5 times for males (Morgan et al., 1975).

Despite Pattison \& Kahan's (1983) findings that acts of self-mutilation are almost equally divided between the sexes (they found in their sample that males constituted $51 \%$ and females $49 \%$ ), most research suggests that 'moderate self-mutilation' is a predominantly female affair. Indeed, Favazza \& Conterio (1988) reveal the typical subject to be a 28-year-old Caucasian female who first selfharmed as young as 14 years and does so repeatedly.

Quite why it should be a predominantly female activity is debatable and no doubt papers have been attempted from this perspective: it is not feasible to discuss this perspective here. In general, however, we agree with Pembroke (1991), who believes that women ultimately repress their needs and that self-mutilation is a kind of 'reclaiming ritual' (Vale \& Juno, 1989) which helps them maintain a sense of their being separate and, for some, provides an end to their neediness (Harrison, 1994). Adolescents may face different demands in terms of their gender: females may be less likely than males to convert their anger into aggression against others; females may take advantage of their stereotypical imagery as weak and ineffective and thus 'act pathetically'; an inability to conform to conflicting social mandates in respect of changing female roles may also induce panic and self harm. Ross (1995) accepts that the majority of self-mutilators are women but agrees with Frost (1995) that many males are 'diagnosed' as 'accidents', thus skewing the overall picture.

Whatever the eventual outcome of this aspect of the issue, currently both Frost (1995) and Ross (1995) ask that question often conveniently ignored: if predominantly women, then why? Whilst many writers agree on the centrality of 'low self-regard' amongst self-mutilators, issues of gender and power remain largely unexplored (see Frost (1995) for an introductory discussion on 'the reasons why').

\section{Self-mutilation: antecedents and repercussions}

Simpson (1980) defines self-mutilations as behaviour producing physical injury to the person's own body, regardless of apparent or supposed intent. It may involve removing, destroying, disfiguring or impairing the appearance of some body part or parts. However definitive this seems, and whilst over the past two decades more than 250 articles and five books have tried to deal exclusively with it, the topic remains fundamentally problematic and resistant to any true understanding. We believe that it is important for nurses to understand the problematic history this area has endured if they are going to work effectively - to the extent that this is possible - with affected individuals.

There is, in fact, no universally agreed definition and over the years clinicians have wandered through autoaggression, intentional self-injury, malingering, Munchausen's syndrome, symbolic wounding, masochism, deliberate selfmutilation, local self-destruction, delicate self-cutting, parasuicide, attempted suicide and focal suicide. Each of these has been interpreted within the context in which each researcher reviewed it. However, the over-riding approach has been medical/clinical in nature. Winchel \& Stanley (1991), for instance, typically categorize self-mutilation within clinical contexts most recognizable to psychiatric nurses. We, however, would support Favazza \& Rosenthal's (1993) contention that clinical perspectives fail to:

capture the self-mutilative behaviours associated with a variety of ... conditions other than psychosis and character disorder. (p. 134)

Other than in cases of psychoses or severe depression, we believe that clinical constructs are probably erroneous.

Alternative, nonclinical, slants began to appear, unsurprisingly, in the late 1960 s and early 1970 s describing selfmutilative behaviour as 'wrist cutting syndrome' (Crabtree, 1967; Graff \& Mallin, 1967; Rosenthal et al., 1972). This was a departure in as much as it dropped the timeworn association with psychoses, depression and so on. Even at this juncture, however, ongoing studies were flawed in that they still failed to distinguish between mutilative acts and failed suicide attempts (Clendenin \& Murphy, 1971; Weismann, 1974). Indeed, this incorrect correlation between failed suicide and self-mutilation lingers on, representing a persistent failure to make a distinction between two very differently motivated acts.

At the same time, we must avoid devaluing the meaning of moderate self-mutilation by splitting off completely the suicidal dimension. Morgan (1979) observes how some distinguish between 'genuine' and 'non-genuine' acts on the basis that the more the act appears aimed at others (in whatever sense) the less genuine it becomes. This fallacy is hardly lessened by considerations that some self-harmers ultimately kill themselves: we need rather to emphasize that acts of self-mutilation are in their own right genuine. Indeed, it occurs to us that in an age less enraptured by the spoken word - as is our own - self-mutilative acts might work more effectively as communicative devices. Menninger 
(1936) perhaps comes closest to the understanding which we seek when he states that:

mutilation is an attempt at self healing ... local self destruction being a form of partial suicide so as to avert total suicide. (p. 271)

\section{Different emphases}

In the 1990s, the emphasis has switched yet again, the prevailing tendency being to link mutilative acts with personality disorders. The DSM-III (Rev) (1987) Diagnostic and Statistical Manual of Mental Disorders lists self-mutilative behaviour as a symptom of borderline personality disorder, multiple personality disorder and sexual masochism. It also defines it as a fictitious disorder with physical symptoms. However, despite the apparent return to a strict medicalization, the predominant view is that self-mutilation is:

a disorder of impulse control ... a distinct syndrome by which self mutilative acts become established as repetitive responses to disturbing psychological symptoms or environmental events. (Favazza \& Rosenthal, 1990, p. 81)

Pattison \& Kahan (1983) concur, stating its essential features as a recurrent failure to resist impulses to harm oneself physically and without conscious suicidal intent. Its primary aim is that of tension release, and once this has been achieved the behaviour is repeated, thus reinforcing self-mutilation as an effective coping strategy and indeed a strategy which may well evolve into an addiction. Not all writers give it this degree of exclusivity however. Siomopoulos (1974) and Lacey \& Evans (1986), for example, see it as inextricably linked with other impulsive disorders such as bulimia, gambling and alcoholism: 'thus', they say, 'if alcohol abuse is addressed, the patient may stop drinking but move to food or cutting' (p. 68). Frost (1995), alternatively, places self-mutilation within a framework of childhood:

I view self destructiveness as a necessary coping (defence) mechanism, resulting from the impossibility of making sense of human - especially childhood experiences. As such, they are chronically an integral feature of survival: everybody has them. (p. 3)

We shall return to this view at the end; for the moment, its psychoanalytic bent and fashionable preoccupation with child abuse seems to us too facile a shift towards theory and away from the practicalities of self-mutilation or our responses to it. We contend that much 'clinical philosophising' (by doctors and nurses) about self-mutilation contributes little to our understanding of it and that we need to turn to self-mutilators themselves. This would afford some insight as to why people cut themselves and might even point towards some profitable approaches to care.
However, the general position, we concede, is unclear and little can be asserted with much degree of confidence. Certainly, it is vitally important to establish why people cut themselves. If Pawlicki \& Gaumer (1993) are right that clients are much more than the sum of their incidents of self-mutilation, then we should access the reasons and observations provided by clients themselves. This is a very neglected area and whatever benefit might accrue from it, to dwell exclusively on clinical perspectives is certainly a mistake (see Morgan (1979, Ch. 10) for a discussion on possible causes). It is not a question of pushing psychiatry aside (as a jealous manoeuvre or whatever), it is simply that wider, person-centred perspectives do not complement medical approaches in this area. We readily believe Pembroke (1991), who states in respect of medical/nursing 'therapies' that her:

world view and experience of living were unimportant. My distress was acknowledged only within a medical framework which I do not share ... my way of dealing with the official version of reality was unacceptable. My entire experience was objectified in a way I found dehumanising. I was never listened to. (p. 30)

\section{Personal accounts}

Whilst self-mutilation can be seen as a 'supremely economical technique whereby a delicate dermal injury can serve multiple psychological functions' (Burrow, 1994, p. 384), recent reports from mutilators themselves are more homogeneous. For instance, whilst cutting is the preferred method, $75 \%$ of clients report that they use multiple means, from burning to gouging. They also report many episodes as well as a low level of lethality; importantly, suicide is not their aim (McEvedy, 1963). Although freely available, such personal accounts rarely influence practical care, possibly due to the overall punitive reactions of practitioners.

The commonest reason given by clients who self-mutilate is that of tension release (Gardner \& Gardner, 1975; Favazza, 1989; van Moffaert, 1990; Allen, 1995). One client stated, 'before every act of self-mutilation I feel overwhelmed. The sight of blood seems to release unbearable tension' (Favazza, 1989, p. 139). Secondly, just prior to the self-mutilative act, clients express feelings of being cut off from life and feeling less of a person. The act of harming and the sight of blood therefore presumably allow some hold on reality. Also, their feelings of estrangement perhaps account for the very high pain thresholds which they report. It would seem that self-mutilating affords a level of control, both over extreme emotions as well as over a threatening environment; it offers a sense of uniqueness 
and security and enables people to vent their anger and rage on their own bodies. In this instance, it can be seen as a safety valve, 'a relieving enactment of revenge' according to Favazza (1989), against significant others who have abused them either emotionally, physically or sexually: in particular, it correlates highly with childhood abuse (Van der Kolk, 1987; Frost, 1995). In respect of this, Shapiro (1987) proposes that self-blame and self-punishment are the mediating processes between sexual abuse and self-mutilation in which the:

child learns, as a result of being abused, the behaviours and cognitions appropriate for being abused and incidentally for abusing. (Clarke \&

Llewelyn, 1994, p. 274)

Clients frequently report low self-esteem and a high degree of hopelessness, a picture born out by studies (using the Beck Depression Inventory (Beck et al., 1961)) which show that depression is a common characteristic (Dyer \& Kreitman, 1984). However, this depression represents how the person feels at the time of cutting rather than depression as an ongoing state of mind. Without wishing to excessively deprecate the numerous medical/psychiatric explanations - biological, psychological, psychodynamic, behavioural and so on - we would unhesitatingly opt for Ross's final rejoinder:

I'll tell you what self harm isn't. It's not masochistic, it's not attention seeking. It's rarely a symptom of so called psychiatric illness.... It's not silly and definitely not selfish. It's about trying to create a sense of order out of chaos. It's a visual manifestation of extreme distress. (in Pembroke, 1991, p. 31)

\section{Nursing care}

In terms of nursing care, firstly, we need to restate that moderate self-mutilation 'is not associated with conscious suicidal intent nor is it a response to a delusion, hallucination or serious mental illness' (Favazza \& Rosenthal, 1990). As such, it needs to be dealt with as a separate entity requiring a distinct nursing management. We need also to acknowledge recent European research which advocates strategies which incorporate a psychiatric element but within an overall medical setting (van Moffaert, 1991). In some countries (e.g. Holland) such an approach can result in all nursing interventions occurring within medical ward settings and by general nursing staff. We mention these approaches because they at least diminish the 'psychiatricization' of self-mutilation and, in many respects, help re-define the behaviour separately from suicide or suicide intent - to which it presently occupies a kind of poor sister role - as well as giving self-mutilative acts a level of serious response.
In the UK, self-mutilation is seen from a purely psychiatric perspective. However, the notion of 'de-psychiatricizing' (and thus de-mythologizing) these behaviours by broad-based responses is certainly worth looking at. Of course, almost all self-mutilation is responded to initially within Accident and Emergency (A \& E) Departments: however, we believe that the act is not seen as strictly a 'proper' medical event at all, and that massive elements of a psychosocial and moral kind are suspected, by professionals, to be involved. Therefore, a precondition to nursing interventions is that nurses themselves discuss their own beliefs and values. Areas such as professional forums, clinical supervision and training sessions can offer nurses invaluable support and education (Childs et al., 1994): prejudices and attitudes can be discussed and Burrow (1994) has shown that such measures as these can prevent a therapeutic stalemate in the care of people who self-harm.

\section{The ward milieu}

Pawlicki \& Gaumer (1993) emphasize environmental as well as emotional support for clients. This is because, for hospitalized clients, the ward milieu may itself act as a precipitating causal factor. Clients often experience feelings of abandonment and rejection, e.g. in respect of different shifts and changes in ward routines. Rosenthal et al. (1972) noted that self-mutilative acts increased during shift changes, when the named nurse was replaced, when key staff were on holidays and at weekends when many residents would be on leave.

The likelihood of self-attacks can increase at certain times of day - during early morning or drawn out afternoons and especially at times when there is less structure or organized activity and, hence, the possibility of greater isolation. Simpson (1975) advocates a coherent and clear policy with one nurse in overall charge but with complete involvement by the team. In this way, clients are enabled to modulate their attachments (Pawlicki \& Gaumer, 1993) and their effective communication within the nursing team. In a later paper, Simpson (1980) highlights communication as a vital supportive ingredient for both clients and nurses involved. Such supportive networks are mostly at risk where clients regress and regression may induce a therapeutic impasse which is difficult to overcome in the short term. Indeed, as Simpson (1980) notes, staff attitudes are often highly aroused after a slashing and can fluctuate between feelings of rage, guilt, sympathy and resentment and a bitter sensation of not being able to cope with a clinical situation. Pao (1969) believed that this could lead to a kind of 'castration anxiety' amongst staff, who are left feeling both impotent and powerless. This anxiety in turn 
may be unconsciously conveyed to the client (Casement, 1985) and may indeed precipitate further acts of selfaggression. The cyclical nature of this anxiety is exacerbated through many clients experiencing, unsurprisingly perhaps, difficulties in verbalization (Simpson (1975) reports as many as $66 \%$ ). Contexts of overwhelming anxiety seriously impede the acquisition of the skill of putting feelings into words. In order to combat this, a therapeutic, nonjudgmental and accepting approach (however banal this sounds) is essential. Clients should be encouraged to express feelings and there should occur a mutual exploration of the factors leading to onset of a crisis (Burrow, 1994). If tension release and sensory stimulation the latter to end feelings of dissociation - are the primary functions of self-mutilating, then these are the needs which must be met during the arousing preverbal stage of increasing anxiety prior to the act itself. If these needs are not met, then clients will resort to their most effective coping skill, namely the act itself (Graff \& Mallin, 1967; Walsh \& Rosen, 1988), that apparent safety valve which serves to unite mind and body (Pawlicki \& Gaumer, 1993).

\section{A more permissive approach}

For some clients, boundaries can be set and short-term contracts negotiated; the latter are more attainable and so are more likely to increase a client's confidence. In general, however, too great an emphasis has been attached to issues of boundaries and contracts. Cremin et al. (1995) stated that:

prior attempts to protect patients from themselves by increasing surveillance, curtailing their freedom, invoking Section 2 and 3 of the Mental Health Act, more often than not led to a hostile stalemate. (p. 237)

These writers substituted an emphasis on transference and counter transference as explanatory mechanisms for the repetitive and addictive nature of self-mutilative acts. A preadmission challenge was devised so as to pre-empt the roles that clients would unconsciously assign to nurses. These attributions would include such fantasized roles as:

an ideal saviour, an all providing, never tiring, constantly available mother, a tyrannical authority figure, and a frightened confused and helpless child. (Cremin et al., 1995, p. 239)

The guidelines to the challenge noted that problems would not evaporate spontaneously and that nurses must anticipate the addictive nature of the problems as well as the client's wish to hand over responsibility to them whilst, conversely, becoming triumphant if they successfully defeated any help available. The emphasis of the challenge was that it was a two-way process with a reversible perspective, with both clients and nurses assessing their emotions three times a day. The challenge proved to be successful in the first week when compared with unchallenged clients. However, there was little disparity between both groups in subsequent weeks. Whilst it failed overall, the study nevertheless highlighted a need for further research.

\section{Blade runners}

From the client's perspective, the most effective management is their autonomy. Ultimately this must mean a basic acceptance that cutting is something that they do. Tacitly we accept that some people abuse drugs and we appropriately supply them with clean syringes. Similarly we should give self-mutilators first-aid kits and clean blades. Pembroke (1991) remarks that 'this was liberating and I started to harm less'. Moreover, clients have stated that if they cut immediately, rather than allowing the tension to rise, there is a reduction in harm and less alarming results. Too many approaches to self-mutilation are therapist-led and damned by the notion that if professionals do not have the answers, then it is merely a question of time until they do: psychiatry, particularly, is riddled with this kind of thinking. We need, rather, to explore ways of giving more responsibility to people who self-mutilate. Indeed, some advocate a complete avoidance of hospital regimes on the basis that hospital environments remove responsibility from patients, reinforce that the patient is ill and expose the patient to what is, very often, a divided staff (Tantam \& Whittaker, 1992).

In general, we think that nurses would benefit from a more permissive approach to this subject. Self-mutilation is a subject which has been in the stranglehold of clinical, diagnostic psychiatry for too long. If clinicians continue to maintain that self-mutilative behaviour is manipulative or attention seeking, if they continue to respond to it with anger and rejection rather than with empathy and understanding, then this will simply provoke further self-mutilations. Of course, society values people who learn to control their feelings, perceptions and bodies (Pembroke, 1991). Preoccupation with the body, fitness and health(ism) has reached almost fetishistic proportions currently. People who injure themselves may be seen as wasteful, frightening, eccentric and selfish. Nurses are an integral part of society and will therefore in their work condone, refute or sanction these values. We seek to question why professionals should hold discriminatory beliefs and how these beliefs may be altered, as well as the implications of beliefs which challenge traditional relationships between nurses and clients. If $\mathrm{A} \& \mathrm{E}$ and psychiatric nurses are to continue to work with people who self-mutilate, then they must become familiar with the area, emphasizing awareness through listening and highlighting issues of available 
resources - such as self-help networks - and communicating this to people who often feel isolated and persecuted because of their behaviour.

\section{Taboo}

Many people appear to believe that self-mutilative behaviour, when not grounded in psychotic or organic aetiology, is manipulative and grossly attention seeking. What is astonishing, however, is the widespread prevalence of such views by the very professionals who are there to help and support the clients (Favazza, 1989). Some clinicians admit their feelings:

The typical clinician, myself included, treating a patient who self-mutilates is often left feeling a combination of helpless, horrified, guilty, furious, betrayed, disgusted and sad. (Francis, 1987, p. 316)

So, in the first instance, we must examine our own selfawareness concerning self-mutilation. We may ask, for example, why training programmes exhibit such a strange neutrality about such a highly prevalent behaviour. Perhaps we can also ensure a flow of information to students from user groups, given that the professional literature displays such clinical bias. Researching this paper, we were not inspired by titles such as 'Affect integration in psychoanalysis: a clinical approach to self harm', nor did we linger over 'The self-injury hypothesis: addressing a neurologist's concerns'. Indeed, a cursory examination of the literature of the past four decades reveals why it has become so difficult to achieve even a modest understanding of selfmutilation. Medical research has been sporadic and prognosis poor, with almost all treatments failing the client as well as frustrating those attempting them.

But it was the nursing attitudes which astonished: attitudes which were, in the main, blinkered and discriminatory. Frost (1995), for instance, reported that self-mutilation:

is often viewed as incomprehensible and regarded with abhorrence. (p. 4)

Similarly, Hawton (1991) is only one of many reporting negative responses in both doctors and nurses. To a large extent, this picture reflects the dominance of medical views in the sense of nonmedical practitioners (until recently) being reluctant to develop their own investigative strategies and interventions. In fairness, there remains considerable scope for determining relative contributions of different disciplines to the culture of $A \& E$ units.

\section{Other reasons}

Whilst those taking overdoses may receive a warmer response, especially if seen as attempted suicide, people who cut are regularly given short shrift. To some extent, economic factors play a role: people who self-harm often do so at weekends when medical and social work cover is low and there is less chance of them being listened to:

When time and resources are limited and no one really knows how best to help, it's easier to make judgements and use labels than to spend time looking for possible causes of distress. (Harrison, 1994, p. 4)

Naturally, such labels can lead to dysfunctional attitudes towards patients who are so labelled (Moss, 1988), and Allen (1995) observed that dysfunctional attitudes such as these were the reason why self-mutilators often receive such a poor service from professional services.

A method by which self-mutilators seek to enhance their expectation of more positive medical/nursing response is to avow a suicide attempt. Favazza (1989) observes that:

patients in need of medical and psychiatric attention may confess to a suicide attempt because they have learned that physicians and nurses confronted with self-mutilation may act in an angry and inappropriate manner. (p. 137)

As stated, these punitive responses merely provoke further self-mutilative acts and van Moffaert (1990) acutely notes that:

Self mutilating clients are particularly sensitive to hostile feelings, especially in medical people ... they feel easily wronged or rejected and they will inevitably express this in further self mutilation. (p. 378)

Kaplan (1971) suggests that beliefs about 'manipulative behaviour' may lead at best to poor nursing interventions or at worst to traumatic and degrading medical attention. McLaughlin (1994) states that inadequate responses jeopardise the essence of therapeutic relationships, namely trust. Ajzen (1988) has always considered that a person's attitude towards another person can constitute a disposition to respond favourably or unfavourably to that person: this unchallenged tenet of social psychology can seem pitifully absent from the medical settings of care for self-mutilators. Louise Pembroke, once a habitual self-mutilator, criticises (her) years of psychiatric mismanagement, incompetence and ignorance. At the height of her cutting, she attended an A \& E department at least twice weekly. She affirms that she would sometimes be sutured without anaesthetic and that she:

was insulted, condemned and even ridiculed and it would take days to recover from the trauma.

(Pembroke, 1991, p. 42)

Since self-mutilators often have low self-esteem anyway (Favazza, 1989), Pembroke (1991) believes that nurses' attitudes merely confirm their lack of self-worth: responses such as condemnation, anger and judgement, states 
Pembroke, are unproductive and merely increase the probability of further self-harming. A further complication, noted by Cooney (1989), is that the humiliation experienced in the A \& E room becomes an integral part of their self-loathing and propensity for even more self-harm.

We conclude that many nursing staff have little sympathy or understanding of this area and may well react punitively (Hanson, 1995). The prevailing attitudes of professionals, well documented in journals and books, are outrageous, all the more so because:

with adequate clinical and attitudinal preparation for these clients, each of us, despite possible feelings of revulsion, is capable, in principle, of regarding a selfmutilating client as having the same health needs as any other client. (Burrow, 1994, p. 383)

Cremin et al. (1995) report that when given an opportunity to look beyond 'presenting symptoms', nurses respond in a less restrictive manner. It is particularly important not to impose that order which nurses traditionally have seen fit to impose when clients become disruptive: people who cut themselves are not a problem to be dealt with, rather they are part of a process (involving significant others at different times) needing to be understood. As Frost (1995) states: medical approaches seek order and will always try to impose it by means of diagnosis; distress is viewed as disorder and placed within its most appropriate, treatable niche. Concessions such as Newson-Smith's (1980) acknowledgement that social workers might be better equipped to deal with the client's interpersonal problems, as well as providing more appropriate responses, are too few and far between.

We have stressed the topic in the sense of seeing it from the self-mutilator's perspective, not so much empathically (since empathy is still something which experts do) but collaboratively in that:

Self harm is not a phenomenon known only to a few who have inflicted injury on their bodies. Self harm involves all of us at some level. We all punish, distract, or numb ourselves as a way of dealing with difficult feelings and situations. (Harrison, 1994, p. 2)

This is not self-indulgent: it means that possible 'solutions' to self-mutilations cannot be brought about through professional theories informing/determining practice. Responses must be tolerant of the inexplicable, open to new learning and, ultimately, informed by users themselves.

\section{References}

Ajzen I. (1988) Attitudes, Personality and Behaviour. Dorsey Press, Chicago.

Allen C. (1995) Helping with deliberate self-harm: some practical guidelines. Fournal of Mental Health 4, 243-250.

Beck A.T., Ward C.H., Mendelson M., Mock J. \& Erbaugh J. (1961)
An inventory for measuring depression. Archives of General Psychiatry 4, 77-87.

Burrow S. (1994) Nursing management of self-mutilation. British Fournal of Nursing 3(8), 382-386.

Casement P. (1985) On Learning from the Patient. Tavistock/ Routledge, London.

Childs A., Tibbles P. \& Thomas B. (1994) Specialist needs. Nursing Times 90(3), 32-33.

Clarke S. \& Lleweyln S. (1994) Personal constructs of survivors of childhood sexual abuse receiving cognitive analytic therapy. British Journal of Medical Psychology 67, 273-289.

Clendenin W.W. \& Murphy G.E. (1971) Wrist cutting: new epidemiological findings. Archives of General Psychiatry 25, 465-469.

Cooney G. (1989) Looking at self-harm. Survivors Speak Out Conference. Unpublished Paper.

Crabtree L.H. (1967) A psychotherapeutic encounter with a selfmutilating patient. Psychiatry 30, 91-100.

Cremin D., Lemmer B. \& Davidson S. (1995) The efficacy of a nursing challenge to patients: testing a new intervention to decrease self harm behaviour in severe personality disorder. Fournal of Psychiatric and Mental Health Nursing 2, 237-246.

DSM-III (Rev) (1987) Diagnostic and Statistical Manual of Mental Disorders, 3rd edn, revised, DSM-III-R. American Psychiatric Association, Washington, DC.

Dyer J.A.T. \& Kreitman N. (1984) Hopelessness, depression and suicidal intent in parasuicide. British Fournal of Psychiatry 154, 41-47.

Favazza A. (1987) Bodies Under Siege: Self-mutilation in Culture and Society. Johns Hopkins University Press, Baltimore.

Favazza A. (1989) Why patients mutilate themselves. Hospital and Community Psychiatry 40, 137-145.

Favazza A. \& Conterio K. (1988) The plight of chronic self-mutilators. Community Mental Health fournal 24, 22-30.

Favazza A. \& Rosenthal R.J. (1990) Varieties of pathological selfmutilation. Clinical Behavioural Neurology 3, 77-85.

Favazza A. \& Rosenthal R.J. (1993) Diagnostic issues in selfmutilation. Hospital and Community Psychiatry 44(2), 134-140.

Francis A. (1987) The borderline self-mutilator: introduction. Journal of Personality Disorders 1, 316.

Frost M. (1995) Self-harm and the Social Work Relationship. Monograph 134. Social Work Monographs, Norwich NR4 7TJ.

Gardner A.R. \& Gardner A.J. (1975) Self-mutilation, obsessionality and narcissism. British Fournal of Psychiatry 127, 127-132.

Graff H. \& Mallin R. (1967) The syndrome of the wrist cutter. American fournal of Psychiatry 124, 36-42.

Hanson M. (1995). Letting out the big scream. In Self-harm and the Social Work Relationship (Frost M., ed.). Monograph 134. Social Work Monogrpahs, Norwich, NR4 7TJ.

Harrison D. (1994) Understanding Self-harm. Mind Publications, London.

Hawton K. (1991) Repetition and suicide following attempted suicide. In Current Approaches: Suicide and Attempted Suicide, Risk Factors, Management and Prevention (Montgomery S.A. \& Goeting N.L.M., eds). Duphar Medical Relations, Gater's Hill, West End, Southampton.

Kaplan M. (1971) Context effects in impression formation. Fournal of Personality and Social Psychology 19, 92-99.

Lacey J.H. \& Evans L.D.H. (1986) The impulsivist: a multiimpulsive personality disorder. British Fournal of Addiction 81, 641-649. 
McEvedy C. (1963) Self-inflicted injury. Unpublished D.P.M. Dissertation, University of London.

McLaughlin C. (1994) Casualty nurses' attitudes to attempted suicide. Fournal of Advanced Nursing 20, 1111-1118.

Menninger K.A. (1936) Man Against Himself. Harcourt Brace \& World, New York.

van Moffaert M.M. (1990) Self-mutilation: diagnosis and, practical treatment. Fournal of Psychiatry in Medicine 20(4), 373-382.

van Moffaert M.M. (1991) Integration of medical and psychiatric management of self-mutilation. General Hospital Psychiatry 13, 59-67.

Morgan H.G. (1979) Death Wishes? The Understanding and Management of Deliberate Self-harm. John Wiley, Chichester.

Morgan H.G., Pocock H. \& Pottle S. (1975) The urban distribution of non-fatal deliberate self-harm. British Fournal of Psychiatry 126, 319-328.

Moss A. (1988) Determinants of patient care: nursing process or nursing attitudes. Fournal of Advanced Nursing 13, 615-620.

Newson-Smith J.G.B. (1980) The use of social workers as alternatives to psychiatrists in assessing parasuicide. In The Suicide Syndrome (Farmer R. \& Hirsch S., eds). Croom Helm, London, pp. 215-225.

Pao P.N. (1969) The syndrome of delicate self-cutting. British Fournal of Psychology 42, 195-206.

Pattison E.M. \& Kahan J. (1983) The deliberate self-harm syndrome. American Fournal of Psychiatry 140(7), 867-872.

Pawlicki C.M. \& Gaumer C. (1993) Nursing care of the self-mutilating patient. Bulletin of the Menninger Clinic 57, 380-389.

Pembroke L. (1991) Surviving psychiatry. Nursing Times 87(49), 30-32.

Podvoll E.M. (1969) Self-mutilation within a hospital setting: a study of identity and social compliance. British Fournal of Psychology 42, 213-221.

Robertson M.M., Trimble M.R. \& Lees A.J. (1989) Self-injurious behaviour and Giles de la Tourette syndrome. Fournal of Psychological Medicine 19, 611-625.
Rosenthal R.J., Rinzler C., Walsh R. \& Klausner E. (1972) Wrist cutting syndrome: the meaning of a gesture. American fournal of Psychiatry 128, 1363-1368.

Ross M. (1995). Shocking habit: the company. In Self-harm and the Social Work Relationship (Frost M., ed.). Monograph 134, Social work Monographs Norwich, NR4 7TJ.

Shapiro S. (1987) Self-mutilation and self-blame in incest victims. American fournal of Psychotherapy 41, 46-54.

Simpson M.A. (1975) The phenomenology of self-mutilation in a general hospital setting. Canadian Fournal of Psychiatry 20, 429-434.

Simpson M.A. (1976) Self-mutilation. British Fournal of Hospital Medicine 16, 430-438.

Simpson M.A. (1980) Self-mutilation. Temple University Press, Philadelphia.

Siomopoulos V. (1974) Repeated self-cutting: an impulse neurosis. American Journal of Psychotherapy 28, 85-94.

Tantam D. \& Whittaker J. (1992) Personality disorder and selfwounding. British Fournal of Psychiatry 161, 451-464.

Vale V. \& Juno A. (1989) Modern Primitives. Research Publications, San Francisco.

Van der Kolk B.A. (1987) Psychological Trauma. American Psychiatric Press, Washington, DC.

Walsh B.W. \& Rosen P.M. (1988) Self-mutilation: Theory, Research and Treatment. Guildford Press, New York.

Weismann M.M. (1974) The epidemiology of suicide attempts, 1960-1971. Archives of General Psychiatry 30, 737-746.

Wexler L., Weismenn M.M. \& Kasl S.V. (1978) Suicide attempts 1970-1975: updating a United States study. British fournal of Psychiatry 132, 180-185.

Winchel R.M. \& Stanley M. (1991) Self-injurious behaviour: a return to the behaviour and biology of self-mutilation. American Fournal of Psychiatry 148, 306-317. 